\title{
Gestão democrática, participação popular e controle social: análise das emendas paranaenses ao documento referência da Conae 2014
}

\author{
Democratic Administration, popular participation and social \\ control: analysis of the Paraná state's amendments to the \\ Reference Document of Conae 2014
}

Gestión democrática, participación popular y control social: análisis de las enmiendas del Estado del Paraná a el Documento Referencia de la Conae 2014

\section{Adriana Dragone Silveira' Taís Moura Tavares ${ }^{2}$}

\section{Resumo}

Este artigo tem por objetivo apresentar uma análise das propostas de emendas paranaenses ao Documento Referência da Conferência Nacional de Educação (Conae) 2014, para o eixo "Gestão democrática, participação popular e controle social". O caderno de emendas preparado para a discussão na Conferência Estadual de Educação do Paraná, para o eixo em destaque constou com 356 sugestões. Da análise se destacam as emendas referentes: à participação popular por meio de Conselhos; sobre os mecanismos de participação na promoção da democratização da gestão dos sistemas de ensino e das instituições escolares; ao destaque do setor público na gestão da educação e dos seus recursos; à alternância nos postos de gestão das instituições escolares e à autonomia da escola na gestão dos recursos financeiros.

Palavras-chave: Gestão democrática; Participação popular; Controle social; Conae 2014;

\begin{abstract}
This article aims to present an analysis of the state of Paraná proposed amendments to the Reference Document of the National Conference on Education (Conae) in 2014, to the theme "Democratic administration, popular participation and social control". The amendments documents prepared for discussion at the Paraná State Conference of Education consisted with 356 suggestions. From the analysis we highlight the related amendments: popular participation through councils; about the mechanisms of involvement in promoting democratization of the management of education systems and school institutions; the highlight of the public sector in management education and its resources; the alternation in principal's at public schools positions; and school autonomy in the management of financial resources.
\end{abstract}

Keywords: Democratic administration; Popular participation; Social control; Conae 2014.

1 Doutora em educação, professora e pesquisadora do Núcleo de Políticas Educacionais (NuPE) e do Programa de Pós-Graduação em Educação (PPGE) da UFPR; e-mail: adrianadragone@yahoo.com.br

2 Doutora em educação, professora e pesquisadora do Núcleo de Políticas Educacionais (NuPE) e do Programa de Pós-Graduação em Educação (PPGE) da UFPR; e-mail: tavarestais@gmail.com 


\section{Resumen}

Este artículo tiene como objetivo presentar un análisis de las propuestas de enmienda hechas por el estado de Paraná al documento de referencia de la Conferencia Nacional de Educación (Conae) en 2014, sobre el eje "Gestión democrática, la participación popular y el control social". Los documentos preparados para su discusión en la Conferencia de Educación del Estado de Paraná, para el eje consistían con 356 sugerencias de alteración. Del análisis se destacan las modificaciones relacionadas: la participación popular a través de los consejos; sobre los mecanismos de participación en la promoción de la democratización de la gestión de los sistemas educativos y las instituciones escolares; el destaque del sector público en la gestión de la educación y sus recursos; la alternancia en los cargos directivos de las instituciones educativas; y la autonomía escolar en la gestión de los recursos financieros.

Palabras-clave: Gestión democrática; Participación popular; Control social; Conae 2014.

A aceitação da democracia como valor nos processos de definição dos rumos das sociedades modernas é hoje consensual. No Brasil, marcado por vários episódios de regimes de exceção, em que direitos civis e políticos foram restringidos por governos autoritários, atingimos um estágio em que todos se declaram democráticos.

Nos parâmetros do estado liberal, a democracia constitui-se a partir de alguns critérios ainda não consolidados na prática e na cultura política brasileira. Segundo Robert Dahl (2001), os critérios de um processo democrático são cinco: a) participação efetiva, entendida como iguais oportunidades de que cada um possa expressar sua posição; b) igualdade de voto; c) entendimento esclarecido, ou seja, oportunidades de compreender as alternativas em disputa e suas consequências; d) exercício do controle efetivo sobre o planejamento das políticas; e) inclusão de todos os adultos nos processos decisórios. A base desses critérios é o princípio da igualdade intrínseca:

"Devemos considerar o bem de cada ser humano intrinsecamente igual ao de qualquer um". [...] como julgamento moral insistimos que a vida, a liberdade e a felicidade de uma pessoa não são intrinsecamente superiores ou inferiores às de qualquer outra. Consequentemente, devemos tratar todas as pessoas como se possuíssem igual direito à vida, à liberdade, à felicidade e a outros bens e interesses fundamentais. Chamarei esse julgamento moral de princípio da igualdade intrínseca (DAHL, 2001, p.78, grifos do autor).

Pode um país com históricas desigualdades sociais, culturais e econômicas ser efetivamente democrático? Ultrapassar a democracia formal estabelecida no plano legal na direção de uma democracia efetiva tem sido o desafio no contexto atual, tanto no plano do funcionamento do Estado e da sua relação com a sociedade civil, quanto no que se refere especificamente à democratização da educação.

Com a redemocratização da sociedade brasileira, no final dos anos 1970 e 1980, as demandas em educação centram-se na democratização do acesso à educação, na defesa do ensino público de qualidade e na participação popular na gestão da educação e da escola, visando romper com as práticas autoritárias e centralizadoras, de participação restrita e formal, construindo e aperfeiçoando espaços democráticos para a partilha do poder e controle social.

Na Constituição Federal de 1988, a República Federativa do Brasil constitui-se em Estado Democrático de Direito. Segundo José Afonso da Silva (2001), um Estado de Direito tem como características básicas a submissão do poder estatal à lei, a separação de poderes e a enunciação e a garantia dos direitos individuais. Já um Estado Democrático tem como base o princípio da soberania popular na formação das instituições representativas, mas também visa à garantia dos direitos fundamentais da pessoa humana como realização do princípio democrático. Na definição do Estado brasileiro, a expressão "democrático de direito" tem como pressuposto que o 'democrático' qualifique o Estado, portanto irradiando os valores da democracia sobre todos os elementos constitutivos do Estado e também sobre a ordem jurídica" (SILVA, 2001, p.123). 
Quando refletimos sobre o campo da educação e da escola, observamos que os princípios democráticos presentes na Constituição Federal estendem-se aos processos educacionais. Neste sentido, sendo a democracia a base do Estado brasileiro e das suas instituições, o princípio da "gestão democrática do ensino público" é um reforço à concepção de Estado brasileiro adotado pela Carta Constitucional de 1988.

A Lei de Diretrizes e Bases da Educação Nacional (LDB), de 1996, reafirma como princípio "a gestão democrática do ensino público na forma desta Lei e da legislação dos sistemas de ensino" (BRASIL, 1996, art. $3^{\circ}$, VIII). E no artigo 14 estabelece os princípios norteadores das "normas de gestão democrática do ensino público na educação básica" pelos sistemas de ensino:

I - participação dos profissionais da educação na elaboração do projeto pedagógico da escola;

II - participação das comunidades escolar e local em conselhos escolares ou equivalentes (BRASIL, 1996, art. 14).

Vemos aqui como o plano legal ainda apresenta restrições à participação de todos, contrariando os princípios anteriormente expostos: a participação para a elaboração do projeto pedagógico, segundo a LDB restringe-se aos profissionais da educação. Nesse sentido, apresenta um retrocesso, em termos conceituais, ao estabelecido pelo Estatuto da Criança e do Adolescente (ECA), de 1990, que assegura como "direito dos pais ou responsáveis ter ciência do processo pedagógico, bem como participar da definição das propostas educacionais" (art. 53, parágrafo único).

O sentido de autonomia também é marcado por controvérsias. A autonomia é um elemento fundamental no exercício da democracia, com participação de seus usuários na tomada de decisões, no sentido, como afirma Paro (2001, p. 84), "que a escola seja detentora de um mínimo de poder de decisão que possa ser compartilhado com seus usuários com a finalidade de servi-los de maneira mais efetiva". A LDB trata da autonomia das escolas face aos sistemas de ensino:

Os sistemas de ensino assegurão às unidades escolares públicas de educação básica que os integram progressivos graus de autonomia pedagógica e administrativa e de gestão financeira, observadas as normas gerais do direito financeiro público (BRASIL, 1996, art. 15).

Entretanto, é preciso considerar que essa autonomia é sempre "relativa", pois a escola segue a legislação referente às normas do direito administrativo e público e no aspecto pedagógico as bases mínimas de conteúdos curriculares nacionais. É essa base que assegura, por outro lado, a unidade de qualidade que atende ao princípio de igualdade.

Ao mesmo tempo, a "autonomia da escola" tem sido mecanismo de aprofundamento das desigualdades quando serve para justificar processos de desresponsabilização do poder público em relação à manutenção das unidades escolares. Cabe ressaltar que autonomia não pode ser confundida, como destaca Paro (2001, p. 83-4), com "abandono e privatização" no que concerne ao Estado ser desresponsabilizado de suas tarefas e "descentralização de poder" com "desconcentração das atividades e procedimentos de cunho meramente executivo", devendo a escola ser detentora de "um mínimo de poder de decisão que possa ser compartilhado com seus usuários".

Os múltiplos sentidos com os quais têm sido usados os termos como "autonomia" e "participação" intensificam a disputa pelos conceitos do que seja "democrático" no campo da sociedade e consequentemente da escola. Essa disputa tem sido objeto da reflexão teórica, mas também da proposição e realização de novas práticas no interior das instituições escolares e sistemas de ensino que se expressam nos espaços coletivos de definições sobre as políticas educacionais como foi o caso da Conferência Nacional de Educação (Conae).

Visando à construção e ao aperfeiçoamento dos espaços democráticos de controle social e de tomada de decisão, algumas experiências se destacam, como a realização de assembleia da comunidade escolar; constituição e fortalecimento das atribuições do conselho de escola e grêmio estudantil; participação da comunidade local e escolar, inclusive de pais, comunidade e alunos, na elaboração e implementação do projeto político pedagógico, regimento escolar e currículo; orçamento escolar democrático; eleição/escolha dos dirigentes escolares por meio de consulta aos usuários. Alguns desses processos estão destacados no Documento Referência da Conae 2014: 
Ao conceber a educação e as instituições educativas como espaço público de expressão de concepções e interesses múltiplos, a perspectiva democrática pressupõe uma estrutura organizacional diferente daquela defendida e praticada pela visão conservadora. Na perspectiva democrática, a educação e as instituições educacionais passariam a considerar a horizontalidade nas relações de poder, a alternância nos postos de comando e das funções a serem desempenhadas, a visão geral dos objetivos a realizar e a solidariedade na execução de suas ações, para alcançar os objetivos coletivamente definidos e a qualidade socialmente referendada (BRASIL, 2013, p. 68).

A democratização da gestão educacional visa romper com tradições e lógicas autoritárias e centralizadoras, para tanto se faz necessária a participação popular, com a representação paritária dos diferentes atores, tanto nos colegiados escolares por professores, funcionários, alunos, pais e comunidade, como nos fóruns e conselhos decisórios de políticas públicas educacionais por gestores públicos, trabalhadores e organizações da sociedade civil. Outro elemento essencial para a participação relaciona-se aos processos democráticos de escolha dos representantes, coibindo práticas de indicação e/ou direcionamento dos participantes destes conselhos e fóruns, assim como na proibição de parentes dos gestores públicos na sua composição, pois a manutenção destas práticas não garante "o controle social dos processos educativos, o compartilhamento das decisões e do poder, configurando-se muito mais como mecanismo legitimador de decisões já tomadas centralmente" (BRASIL, 2013, p. 68).

Outro aspecto fundamental para a construção da democracia em nossas instituições refere-se ao controle social. Para tanto, se faz necessário aperfeiçoar o papel fiscalizador dos recursos públicos educacionais dos Conselhos Estaduais e Municipais de Educação, com transparência na aplicação dos recursos públicos, pelos órgãos administrativos centrais e também pelas unidades escolares, com publicização dos orçamentos e das prestações de contas em linguagem acessível, assim como a realização de audiências públicas. Nesse processo é essencial que os conselhos se fortaleçam em suas funções e seus membros sejam capacitados.

Considerando que a democracia "nunca é o fruto de uma evolução natural e inelutável da sociedade política", mas se "institucionaliza ao longo de um incessante e penoso trabalho de modelagem das instituições políticas, em defesa da dignidade humana" (COMPARATO, 1998, p.48), a realização das conferências municipais e estaduais, com ampla participação popular, como meio de preparação para a Conae/2014, nas quais se debateram concepções, proposições e estratégias para o eixo "Gestão democrática, participação popular e controle social", constituiu um importante mecanismo para o fortalecimento da democracia na educação e em nosso país. Dessa forma, este artigo tem por objetivo apresentar uma análise das propostas de emendas paranaenses ao Documento Referência da Conae 2014 referentes a este eixo.

\section{Propostas de emendas das Conferências Municipais e Intermunicipais do estado do Paraná para o eixo "Gestão Democrática, participação popular e controle social"}

O estado do Paraná realizou 220 conferências municipais e intermunicipais, o que demonstra a forte mobilização no estado para a discussão do Documento Referência da Conae 2014, como um elemento fundamental para a consolidação da democratização da gestão na educação, por meio da discussão coletiva das políticas educacionais. Ao todo foram 18.000 propostas de emendas ao documento.

O caderno de emendas (PARANÁ, 2013) preparado para a discussão na Conferência Estadual de Educação do Paraná, ocorrida em setembro de 2013, compõe-se de dois volumes: I) das emendas aprovadas em no mínimo 20\% ou 44 conferências municipais que o Fórum Estadual de Educação recomenda à aprovação; II) das emendas passíveis de destaque na Conferência Estadual do Paraná, aprovadas em menos de $20 \%$ ou 44 conferências municipais ou intermunicipais.

Para o Eixo V "Gestão democrática, participação popular e controle social", das emendas com aprovação em no mínimo 20\% das conferências municipais e que o Fórum Estadual de Educação recomendou para aprovação, houve somente uma, que tratava da ampliação dos programas de apoio e formação aos/às conselheiros/as, de caráter supressivo, pois havia coincidência entre dois parágrafos. 
Já as emendas deste eixo, aprovadas em menos de 20\% das conferências, totalizaram 356 propostas no estado do Paraná, conforme quadro a seguir. O maior percentual de alterações concentrou-se em emendas aditivas. Com exceção de dois parágrafos deste eixo (350 e 360), nos quais não houve proposta de modificação ao texto do documento referência, todos os demais apresentaram sugestões.

Quadro 1 - Quantitativo das emendas propostas ao Eixo V "Gestão democrática, participação popular e controle social”

\begin{tabular}{|c|c|c|c|c|}
\hline PARÁGRAFOS & $\begin{array}{l}\text { QUANTIDADE DE } \\
\text { EMENDAS }\end{array}$ & $\begin{array}{c}\text { EMENDAS } \\
\text { SUPRESSIVAS }\end{array}$ & EMENDA: ADITIVA & $\begin{array}{l}\text { TIPO DE EMENDA } \\
\text { SUBSTITUTIVA }\end{array}$ \\
\hline 349 & 1 & 0 & 1 & 0 \\
\hline 350 & 3 & 0 & 3 & 0 \\
\hline 351 & 0 & 0 & 0 & 0 \\
\hline 352 & 2 & 0 & 1 & 1 \\
\hline 353 & 6 & 2 & 3 & 1 \\
\hline 354 & 4 & & 4 & 0 \\
\hline 355 & 6 & 2 & 3 & 1 \\
\hline 356 & 8 & 0 & 5 & 3 \\
\hline 357 & 2 & 0 & 2 & 0 \\
\hline 358 & 2 & 0 & 1 & 1 \\
\hline 359 & 2 & 0 & 1 & 1 \\
\hline 360 & 0 & 0 & 0 & 0 \\
\hline 361 & 26 & 0 & 23 & 3 \\
\hline 362 & 21 & 2 & 13 & 6 \\
\hline 363 & 46 & 4 & 24 & 18 \\
\hline 364 & 18 & 1 & 16 & 1 \\
\hline 365 & 17 & 2 & 12 & 3 \\
\hline 366 & 13 & 0 & 13 & 0 \\
\hline 367 & 14 & 2 & 12 & 0 \\
\hline 368 & 19 & 2 & 16 & 1 \\
\hline 369 & 9 & 2 & 4 & 3 \\
\hline 370 & 12 & 1 & 9 & 2 \\
\hline 371 & 6 & 1 & 4 & 1 \\
\hline 372 & 13 & 1 & 12 & 0 \\
\hline 373 & 12 & 0 & 11 & 1 \\
\hline 374 & 9 & 1 & 8 & 0 \\
\hline 375 & 15 & 1 & 12 & 2 \\
\hline 376 & 19 & 1 & 13 & 5 \\
\hline 377 & 7 & 2 & 3 & 2 \\
\hline 378 & 8 & 3 & 5 & 0 \\
\hline 379 & 8 & 0 & 7 & 1 \\
\hline 380 & 12 & 3 & 6 & 3 \\
\hline 381 & 16 & 0 & 15 & 1 \\
\hline TOTAL & 356 & 33 & 262 & 61 \\
\hline
\end{tabular}

Fonte: as autoras com base no Caderno de Emendas (PARANÁ, 2013). 
A maior parte das sugestões estava relacionada às propostas para acrescentar e/ou modificar expressões visando aperfeiçoar o texto na realização das ações, como "implementar", "promover", "estimular", "garantir condições técnicas e financeiras". Outras reforçaram a importância da gestão democrática em todas as instituições educacionais, assim com o fortalecimento dos mecanismos de participação e controle social. A seguir apresenta-se análise de algumas dessas emendas.

\section{Participação popular por meio de conselhos}

A proposta de criação de uma comissão nas escolas sobre meio ambiente e qualidade de vida esteve presente no parágrafo 354, ao propor a inclusão de parágrafo novo:

Através de desenvolvimento efetivo, criar e fortalecer as comissões de meio ambiente e qualidade de vida como espaço colegiado democrático da comunidade escolar, para articulação e fortalecimento das questões socioambientais na gestão das instituições educativas e na sua relação com a sociedade (PARANÁ, 2013, p. 181).

Esta discussão também esteve manifesta no parágrafo 367, que trata especificamente sobre a criação e fortalecimento das "comissões de meio ambiente e qualidade de vida, como espaço colegiado democrático da comunidade escolar [...]" (BRASIL, 2013, p. 70). Algumas emendas tratavam sobre a necessidade de incluir financiamento, assim como condições técnicas e financeiras. Uma emenda propunha suprimir todo o parágrafo, no entendimento de que esses temas devem ser abordados pelos outros conselhos já instituídos nas instituições educacionais.

A necessidade de considerar as especificidades de dinâmicas de participação, por diferentes segmentos da sociedade, foi destacada na emenda ao parágrafo 355 ao propor substituir parte do texto, com a seguinte redação:

[...] tendo em vista que há dinâmicas que se caracterizam pelo envolvimento mais restrito a sujeitos ou grupos determinados e outras que se caracterizam por um movimento mais amplo, mediante o qual se busca democratizar os processos decisórios envolvendo diferentes segmentos da sociedade, que há dinâmicas que se caracterizam pelas ações e as tomadas de decisão por meio do trabalho coletivo (PARANÁ, 2013, p. 181).

Sobre a necessidade de reforçar o papel do Conselho de Escola, como órgão máximo de gestão e administração, uma das emendas propôs adicionar ao final do paragrafo 357, que "[...], o conselho escolar deve ser o órgão máximo de gestão das instituições educacionais". Todavia, esta sugestão restringe-se ao Conselho Escolar, não reforçando o papel dos conselhos na gestão da educação como um todo, o que envolve também a gestão do sistema de ensino.

No parágrafo 369, que tratava sobre "Garantir a representação paritária (movimentos sociais e governo) nos fóruns decisórios de políticas públicas educacionais [...]", as propostas tenderam a alterar a expressão "movimentos sociais" para "populares", "entidades de representação dos pais, comunidade escolar", ou alterar "movimentos sociais e governo" para "de gestores públicos, trabalhadores da educação e organizações da sociedade civil". Houve também a proposição de um parágrafo novo, com a seguinte redação:

9.1. Garantir a paridade nos conselhos de Educação (nacional, estaduais e municipais).

9.2. Garantir que as entidades da sociedade civil que farão parte dos conselhos de educação sejam eleitas em conferência.

9.3. Garantir que as indicações das entidades da sociedade civil na composição dos conselhos de educação sejam respeitadas (PARANÁ, 2013, p. 195).

Em relação ao parágrafo 372, que abordava a criação e consolidação de fóruns e conselhos de educação, as emendas propostas destacaram a necessidade de "garantir as condições técnicas e financeiras" e a "forma paritária" de representação dos setores envolvidos. Mas também apresentaram propostas de exclusão total do parágrafo e inclusão de novo sobre as Associações de Pais e Mestres:

Estimular a constituiçã̃o e fortalecimento de associações de pais e mestres e delegar a esse órgão, autonomia a seus membros, no que diz respeito à função da associação, desde que respeitada as Leis vigentes da Instituição de Ensino, para que possam auxiliar a instituição escolar e a comunidade, na busca de soluções para as situações cotidianas em que a escola na pessoa do gestor, pais e sua equipe pedagógica achar necessário (PARANÁ, 2013, p. 196). 
Sobre a Associação de Pais e Mestres, a emenda ao parágrafo 376 requeria a inclusão da palavra "funcionários", pois este termo está presente nas Associações do Paraná.

Ainda sobre os conselhos, uma das emendas ao parágrafo 358 reforçava a necessidade de capacitação e formação dos membros dos conselhos, ao acrescentar ao final: "criando mecanismos de chamamento, capacitação e formação continuada aos membros da comunidade escolar" (PARANÁ, 2013, p. 182).

Como destacado anteriormente, o parágrafo 364 tratava da "ampliação dos programas de apoio e formação aos/às conselheiros/as" foi suprimido. No entanto, em outras conferências, 18 sugestões foram feitas, entre elas destacam-se as que adicionam a garantia de condições técnicas e financeiras para a formação dos conselheiros, inclusive com a previsão de programas de apoio financeiro da União aos municípios para este fim e criação de incentivos financeiros por meio de bolsas para formação e capacitação dos membros dos referidos conselhos, ainda com a precisão de "incentivo financeiro a cada reunião realizada" (PARANÁ, 2013, p. 190).

As principais propostas ao parágrafo 374 referiam-se à inclusão de apoio técnico e financeiro na ampliação dos "programas de apoio e formação aos conselheiros", mas destaca-se também a proposta de supressão do parágrafo todo.

Ainda sobre a capacitação dos membros dos conselhos escolares, a proposta no parágrafo 361 acrescentava: apoio por meio de pró-labore ou bolsa para a capacitação dos membros dos Conselhos.

\section{Mecanismos de promoção da gestão democrática}

No parágrafo 365 enfatiza-se a criação de "mecanismos de participação que promovam a democratização da gestão dos sistemas de ensino e das instituições educacionais, com a participação dos professores, funcionários técnico-administrativos, estudantes, pais e/ou responsáveis e comunidade local". As emendas destacaram substituir "funcionários técnico-administrativos" para "funcionários", "técnicos de apoio" ou "profissionais da educação". Das emendas que propunham adicionar novo parágrafo, destaca-se a que enfatizava a necessidade de:

[...] efetivar mecanismos de gestão democrática, assegurando: eleições diretas para direção de unidades escolares públicas, realização regulares de fóruns e conferências de educação no âmbito de todos os entes federados e dar condições para a efetiva atuação dos conselhos que representam os diversos segmentos da educação (PARANÁ, 2013, p. 191).

No conjunto de emendas ao parágrafo 379, 24 conferências sugeriram incluir a expressão "estudantes", para além de "gestores públicos, trabalhadores da educação e organizações da sociedade civil" na constituição de fóruns para "debater o financiamento da educação e as diretrizes curriculares nacionais".

As emendas ao parágrafo 380 trataram na sua maioria de inclusão de "fóruns permanentes de educação" e 17 sugestões sobre "fóruns permanentes de educação étnico-racial" para "estimular a constituição e o fortalecimento de conselhos escolares e conselhos municipais de educação, como instrumentos de participação e fiscalização na gestão escolar e educacional, inclusive por meio de programas de formação de conselheiros [...]" (PARANÁ, 2013, p. 201).

Entre as propostas ao parágrafo 366, sobre a institucionalização da Conae, estavam as que propunham adicionar "previsão em calendário escolar"; realização a "cada quatro anos", em "lei federal" e após a garantia de "condições técnicas e financeiras" acrescentar: "suficientes para a realização dos eventos, assegurando ampla participação social" (PARANÁ, 2013, p. 192).

As emendas ao parágrafo 368 discutiram sobre a necessidade de não restringir às instituições federais de ensino superior a garantia de que "tenham Plano de Desenvolvimento Institucional (PDI), assim como o projeto pedagógico curricular dos cursos", desta forma sugeriram incluir estaduais, ou estaduais, municipais e privadas ou ainda retirar a expressão "federais", mas também há proposta de incluir o adjetivo "público".

O parágrafo 377 abordava sobre a necessidade de "estabelecer diretrizes nacionais para a gestão democrática da educação" e destacaram-se as emendas para supressão de todo o parágrafo, mas também as que solicitaram a alteração do prazo de dois anos previsto para a aprovação para imediato, e outra para um ano. 
No último parágrafo (381), deste eixo, sobre os mecanismos para promover a gestão democrática no sistema de ensino, o texto estava muito restrito às normatizações da própria LDB, dessa forma, as ementas propunham incluir também "movimentos sociais" ao conjunto com os demais segmentos elencados para a participação: "profissionais da educação, familiares, estudantes e comunidade local". Aos mecanismos previstos no texto base (descritos na citação abaixo), dez propostas de parágrafos novos foram apresentadas:

I) na elaboração ou adequação e implementação dos planos de educação;

II) no apoio e incentivo às instituições educacionais para a construção de projetos político-pedagógicos ou planos de desenvolvimento institucional sintonizados com a realidade e as necessidades locais;

III) na promoção e efetivação da autonomia pedagógica, administrativa e financeira) das instituições da educação básica, profissional, tecnológica e superior (BRASIL, 2013, p. 72).

Entre as emendas aditivas de parágrafo novo destacam-se as que tratam sobre a escolha dos dirigentes das instituições, associações de pais, professores e funcionários, papel fiscalizador dos conselhos com relação aos recursos públicos. Sobre a eleição dos dirigentes:

347 - Texto a Adicionar: Regulamentar, através de lei, a eleição direta para dirigentes das instituições de ensino superior públicas com garantia de paridade de votos entre docentes, técnico-administrativos e estudantes;

348 - Texto a Adicionar: Garantir a eleição dos dirigentes das escolas estaduais e municipais e do Distrito Federal pela comunidade, observando-se a legislação para sua nomeação;

353- Texto a Adicionar: Criar e garantir no prazo de dois anos, a escolha dos gestores das instituições públicas através do voto direto; (PARANÁ, 2013, p. 192).

Inclusão de Associação de Pais, Mestres, Funcionários (APMF) como mecanismo de participação:

349- Texto a Adicionar: Estimular a constituição e fortalecimento de associações de pais e mestres e delegar a esse órgão, autonomia a seus membros, no que diz respeito à função da associação, desde que respeitada as Leis vigentes da Instituição de Ensino, para que possam auxiliar a instituição escolar e a comunidade, na busca de soluções para as situações cotidianas em que a escola na pessoa do gestor, pais e sua equipe pedagógica achar necessário (PARANÁ, 2013, p. 192).

Sobre a composição e atribuições dos conselhos estaduais e municipais de educação na fiscalização dos recursos públicos foram apresentadas as seguintes sugestões de inclusão:

350- Texto a Adicionar: Garantir a constituição democrática dos conselhos estaduais e municipais de educação, contemplando a representação da educação básica, das instituições estaduais de ensino superior, dos trabalhadores da educação e das secretarias de estado, as quais compete a gestão da educação, da ciência, da tecnologia e do ensino superior nos estados e no Distrito Federal.";

351- Texto a Adicionar: Criar mecanismos de Controle Social para acompanhar a destinação dos recursos públicos (Bolsas, PROUNI) para instituições privadas.;

354 - Texto a Adicionar: Garantir o papel fiscalizador dos Conselhos Estaduais e Municipais de Educação no monitoramento das aplicações e prestações de contas dos recursos de ordem federal, estadual e municipal, referentes a fundos, programas e projetos, considerando sua composição e suas atribuições legais;

355 - Texto a Adicionar: Tornar público, por meio de audiências públicas e portais eletrônicos de transparência, especialmente criados para este fim, a organização, o financiamento e as ações de conselhos e de fóruns de educação, no prazo de cinco anos após aprovação do projeto de lei 8035/2010;

356- Texto a Adicionar: Assegurar nas diretrizes orçamentárias em todos os níveis de governo, recursos para capacitação e participação de todos os segmentos dos conselhos contribuídos (PARANÁ, 2013, p. 202).

Uma perspectiva democrática de organização e gestão da educação prescinde de fortalecimento dos mecanismos de participação popular e de controle social, não somente nas instituições escolares, mas fundamentalmente na gestão dos sistemas de ensino municipal, estadual e federal, enfoque este pouco discutido nas emendas deste eixo. Para tanto, reforça-se a necessidade de aprovação de normatização nacional que regulamente a gestão democrática. 


\section{Ressalva ao setor "público" na gestão da educação e dos seus recursos}

Destacam-se no conjunto de emendas deste eixo várias proposições de adjetivar a expressão "público" na gestão da educação e de seus recursos em diferentes contextos. No parágrafo 356, na seguinte frase: "Na perspectiva democrática, a educação e as instituições educacionais 'públicas' passariam a considerar a horizontalidade nas relações de poder" (grifos das autoras). No parágrafo 359 emenda aditiva após a expressão "política nacional de educação" incluindo "pública".

No parágrafo 371 destaca-se a sugestão de suprimir a expressão "privada" no final, o que limitaria a proposição somente às instituições públicas: "criar condições objetivas para o fortalecimento dos conselhos superiores das instituições de ensino superior públicas e privadas" (BRASIL, 2013, p. 71).

Sete propostas de emenda ao parágrafo 373 solicitaram que a autonomia pedagógica, administrativa e de gestão financeira das instituições educativas ficasse restrita ao "público". No parágrafo 376 que abordava a constituição e o fortalecimento de grêmio estudantil e de associação de pais e mestres também houve uma emenda adjetivando no final o "público" para funcionamento destas instituições.

Essas propostas denotam a retomada da discussão da restrição da gestão democrática às instituições públicas, debate vitorioso na Constituinte de 1987-1988. O texto final da Constituição Federal de 1988, ao art. 208, inciso VI, acrescentou-se o adjetivo "público" à gestão democrática, conteúdo este apoiado pelos setores conservadores (ADRIÃO, CAMARGO, 2001), excluindo a gestão democrática ao ensino privado.

No parágrafo 361 constava a inclusão da expressão "público" em "fortalecer os mecanismos e os instrumentos que assegurem a transparência e o controle social na utilização dos recursos públicos aplicados em educação 'pública'", assim como outra proposição de incluir "preferencialmente em instituições de educação pública" (PARANÁ, 2013, p. 183). No parágrafo 379 também constavam proposições para adjetivar educação "pública" no financiamento da educação: "constituir fóruns paritários e regulares, envolvendo gestores públicos, trabalhadores de educação e organizações da sociedade civil, para debater o financiamento da educação 'pública'” (p. 201).

Considerando a previsão legal de repasse de recursos públicos para instituições privadas prevista na Constituição Federal, essas sugestões podem ter o sentido de restrição do monitoramento da aplicação dos recursos públicos nas instituições privadas. Todavia, podem-se compreender essas emendas também no sentido de reforçar o papel do atendimento das políticas do Estado exclusivamente para o setor público.

\section{Alternância nos postos de gestão das instituições escolares}

Três das emendas do parágrafo 356 tratavam sobre a "alternância nos postos de comando e das funções a serem desempenhadas". Uma propunha adicionar a regulamentação da alternância a ser definida em lei posterior, e outras duas acrescentar a eleição direta pela comunidade para diretores de instituições educacionais públicas. Cabe destacar que a alternância foi um dos temas mais reforçados pelos presentes na conferência estadual, dado que a rede estadual e muitas redes municipais no Paraná já realizam eleição para diretores, no entanto a falta de previsão expressa da alternância ou constantes alterações nas regulamentações deste processo permite que muitos profissionais se mantenham no poder, apenas trocando de funções na composição da chapa, ora de diretor ou de vice-diretor.

Ainda sobre a instituição de eleições para diretor, destaca-se a solicitação de acrescentar ao parágrafo 375 a expressão: "garantir a escolha dos gestores escolares, pela comunidade escolar, por meio de eleição direta".

\section{Autonomia da escola na gestão dos recursos financeiros}

No parágrafo 362 que trata da transferência de recursos financeiros à escola entre as emendas que propõem modificações, destacam-se as aditivas sobre a autonomia da escola para destinar os recursos onde for necessário e estabelecimento de norma federal, com critérios simplificados na utilização e prestação de contas dos recursos. Por outro lado, uma emenda propôs retirar o final do parágrafo que estabelecia a finalidade do 
repasse dos recursos às instituições "visando à ampliação da transparência e ao efetivo desenvolvimento da gestão democrática", o que pode denotar um entendimento restrito do repasse de recursos, ou seja, da não compreensão da autonomia financeira como elemento deste princípio (PARANÁ, 2013, p.185).

No mesmo parágrafo 362, sobre a participação da comunidade escolar no planejamento e na aplicação dos recursos, uma emenda propôs sobre a compreensão de "comunidade escolar", reforçando a necessidade da presença de diferentes atores: "professores, funcionários de apoio e técnico administrativo, estudantes, pais e ou responsáveis e comunidade local" (p. 185).

\section{Considerações finais}

As emendas apresentadas nas conferências municipais e intermunicipais paranaenses indicam que ainda estamos instituindo e aperfeiçoando mecanismos que permitam o cumprimento dos critérios de uma democracia liberal no interior dos sistemas de ensino e das unidades escolares.

As indicações sobre quem devem ser os representados pela nominação dos sujeitos - movimentos sociais, funcionários, estudantes etc. - aponta para a não consolidação do critério da inclusão de todos nos processos decisórios. O que se entende por "comunidade escolar" parece estar ainda em definição.

Nas emendas nota-se forte reivindicação por paridade, ou seja, iguais condições de fazer-se representar, manifestar posições e decidir pelo voto. Percebe-se também recorrente preocupação com o provimento de condições prévias ao atendimento dos critérios quando o Documento Referência da Conae 2014 aponta necessidade de capacitação para conselheiros, apoio técnico e financeiro. A formação segue o princípio do entendimento esclarecido (DAHL, 2001), ou seja, da aquisição de compreensão dos processos e conteúdos do que é definido.

A alternância no poder apresenta-se como um aperfeiçoamento da escolha de dirigentes pelo mecanismo de eleição cuja realização iniciou-se, no Paraná, na década de 1980.

Além dessas, duas questões merecem destaque: a do financiamento e da relação público privado. Ambas estão relacionadas, como se pode ver no Documento Referência (BRASIL, 2013).

A tomada de decisão tem como objeto a realização de programas e ações no interior do espaço escolar que não se efetivam na ausência de recursos financeiros que os viabilizem. Tendo em vista a disputa sobre o fundo público, a gestão só é democrática se recair sobre questões efetivas de fazer uma escola com condições de qualidade para todos, o que implica participação nas decisões e controle na execução dos fins e dos meios para que o direito à educação se efetive.

A história das políticas educacionais no Brasil é marcada pela transferência de recursos públicos para o setor privado de ensino. Embora pontualmente os representantes desse setor tenham exercido pressões ocasionais sobre questões de currículo, faixa etária etc., é no que diz respeito ao financiamento que se centram os seus principais interesses.

A presença numericamente superior da representação do setor público nas conferências explica a preocupação com a inclusão do termo "público" e seus efeitos ambíguos no texto.

Entretanto, tal ambiguidade tem raízes para além do texto. Assenta-se na afirmação do dever do Estado no provimento da educação e da sua não realização que se faz pela ausência desse Estado, o que leva a ocupação do espaço de oferta pelo setor privado; e pela promiscuidade entre público e privado, em que o setor privado se mantém e se desenvolve por meio da transferência de recursos públicos.

Seu resultado é a manutenção de altos índices de desigualdade nas condições de qualidade e nos resultados educacionais que se põem tanto como limites quanto como desafios ao processo de aperfeiçoamento da democratização da gestão educacional e escolar.

Desse modo, a discussão do Documento Referência da Conae 2014 em conferências municipais e estaduais é expressão do movimento de conquista de um sentido de democracia que ultrapasse as definições legais, as lacunas normativas e os acúmulos históricos de desigualdade e autoritarismo. 


\section{Referências}

ADRIÃO, T.; CAMARGO, R. B. A gestão democrática na Constituição Federal de 1988. In: OLIVEIRA, Romualdo Portela de; ADRIÃO, T, (Org.). Gestão, financiamento e direito à educação: análise da LDB e da Constituição Federal. São Paulo: Xamã, 2001.

BRASIL. Constituição da República Federativa do Brasil de 1988. 1988. Disponível em: http://www.planalto. gov.br/ccivil 03/constituicao/constituicao.htm. Acesso em: 25 jun. 2014.

Lei $\mathbf{n}^{\circ}$ 8.096, de 13 de julho de 1990. Dispõe sobre o Estatuto da Criança e do Adolescente e dá outras providências. Disponível em: http://www.planalto.gov.br/ccivil 03/leis/18069.htm. Acesso em: 25 jun. 2014.

Lei 9.394, de 20 de dezembro de 1996. Estabelece as diretrizes e bases da educação nacional. Disponível em: http://www.planalto.gov.br/ccivil 03/leis/19394.htm. Acesso em: 25 jun. 2014.

Ministério da Educação. Fórum Nacional de Educação. Conae 2014: Documento Referência. Brasília: Ministério da Educação, Secretaria Executiva Adjunta, 2013. Disponível em: http://conae2014.mec.gov.br/ images/pdf/doc referencia.pdf. Acesso em: 25 jun. 2014.

COMPARATO, F.K.. Ensaio sobre o juízo de constitucionalidade de políticas públicas. Revista de Informação Legislativa. Brasília, ano 35, n. 138, abr./jun. 1998. p. 39-48.

DAHL, R. A. Sobre a democracia. Brasília: Editora Universidade de Brasília, 2001.

PARANÁ. Fórum Estadual de Educação. Caderno de Emendas Paraná ao Documento Referência da II Conae. Disponível em: http://www.app.com.br/portalapp/imprensa/Caderno Emendas Conae PR press.pdf. Acesso em: 25 jun. 2014.

PARO, V. H.. O princípio da gestão democrática no contexto da LDB. In: OLIVEIRA, Romualdo Portela de; ADRIÃO, Theresa (Org.). Gestão, financiamento e direito à educação: análise da LDB e da Constituição Federal. São Paulo: Xamã, 2001.

SILVA, J. A. Curso de Direito Constitucional Positivo. 19 ed. São Paulo: Malheiros Editores, 2001.

Recebido em Novembro de 2014 - Aprovado em Dezembro de 2014 